\title{
Komunikasi Pemasaran Media Sosial Instagram Pada Toko Kue Selebriti Bandung Makuta (@Bandungmakuta) Terhadap Kesadaran Merek
}

\author{
Veby Zilfania Rizal \\ Program Studi Ilmu Komunikasi Program Pascasarjana, Universitas Mercu Buana \\ Jl Meruya Selatan No 1 Jakarta 11650 \\ vebyumb@gmail.com
}

Diterima: Mei, 2019 Direview: Mei, 2019 Diterbitkan: Juni, 2019

\begin{abstract}
Abstrak . Persaingan bisnis melalui media sosial semakin meningkat lebih keras Hal itu bisa dilihat dari meningkatnya jumlah sosial pengguna media. Komunikasi pemasaran menggunakan media sosial ini merupakan salah satu perpaduan New media dan Marketing Communication. Melalui sosial media perusahaan bisa menjangkau konsumen lebih luas salah satunya Instagram. Peluang pemanfaatan media baru, media sosial dalam dunia bisnis disadari oleh para selebriti toko kue para selebriti ini menawarkan konsep, promosi, kemasan, cita rasa yang ditawarkan, serta pemilihan nama untuk oleh oleh kekinian mereka. penelitian ini Menguji korelasi Komunikasi Pemasaran Sosial Media Instagram pada Konsumen Toko Kue Selebriti Bandung Makuta (@Bandungmakuta) pada Kesadaran Merek. Hasil penelitian ini akan merekomendasikan manajemen perusahaan atau organisasi untuk meningkatkan strategi pemasaran khususnya pada media sosial, ditemukan adanya korelasi media sosial Instagram kepada kesadaran merek dan selebriti endoser kepada kesadaran merek, serta secara simultan bersama sosial media dan selebriti endoser mempunyai korelasi terhadap kesadaran merek Toko Kue Selebriti Bandung Makuta (@Bandungmakuta) dengan besaran korelasi 41\%, yang masuk dalam kategori cukup berkorelasi.
\end{abstract}

Kata kunci: Komunikasi Pemasaran,Media Sosial, Kesadaran Merek.

Abstract. Business competition through social media increasingly harder It can be seen from the increasing number of social media users. Marketing communication using social media is one of the blend of New media and Marketing Communication. Through social media companies can reach a wider consumer Instagram one of them. Opportunities for the utilization of new media, social media in the business world are realized by celebrity cake shops these celebrities offer the concept, promotion, packaging, taste offered, and the selection of names for by their present. This study examines the correlation of Social Media Marketing Instagram Media to Consumer Celebrity Cake Shop Bandung Makuta (@Bandungmakuta) on Brand Awareness. The results of this study will recommend the management of companies or organizations to improve marketing strategies, especially on social media, found the correlation of social media Instagram to brand awareness and endoser celebrities to brand awareness, and simultaneously with social media and celebrities endoser has a correlation to brand awareness Cake Shop Celebrities Bandung Makuta (@Bandungmakuta) with a 41\% correlation scale, which fall into the category is quite correlated.

Keywords : Marketing Communication, Social Media, Brand Aware

\section{Pendahuluan}

Persaingan bisnis melalui media sosial semakin meningkat. Hal itu dapat terlihat dengan meningkatnya jumlah sosial pengguna media. Perkembangan ini dapat dilihat dari munculnya pengguna media sosial dalam waktu yang relatif singkat waktu (Tarigan \& Tritama, 2016), Indonesia mengalami peningkatan yang signifikan, riset pada April 2014 menunjukan pengguna internet sebanyak 88 Juta dan pada 2016 mengalami peningkatan sebanyak 132,7 Juta meningkat sebanyak 44 juta pelanggan dalam kurun waktu dua tahun ("Survei Internet APJII 2016," 2016). Salah satu media sosial yang juga fokus pada bisnis adalah Instagram, pertengahan tahun 2016 Instagram secara resmi mengumumkan pembaharuan dan penambahan fitur bisnis pada Instagram. Peluncuran fitur baru ini didasarkan dengan beberapa keberhasilan para pebisnis yang memanfaatkan Instagram sebagai media untuk 
mempromosikan produknya dan berinteraksi dengan para konsumen (Instagram Business Team, 2016).

Komunikasi

pemasaran menggunakan media sosial ini merupakan salah satu perpaduan New Media dan Marketing Communication, menurut Herman Kartajaya untuk mengatur stakeholder dibutuhkan pendekatan baru yaitu marketing 3.0 di mana dahulu hanya satu arah saat ini menjadi kolaborasi dengan one to many dan many to many (Kartajaya, 2013). Melalui sosial media perusahaan bisa menjangkau konsumen lebih luas, selain itu komunikasi pemasaran menggunakan Instagram yang dilakukan oleh pembeli dan penjual sangat membantu didalam pengambilan keputusan dan dapat memberikan masukan kepada penjual untuk lebih baik kedepannya (Hamdan, Ratnasari, Sofyan, \& Tandika, 2017).

Peluang pemanfaatan media baru, media sosial dalam dunia bisnis disadari oleh para selebriti toko kue para selebriti ini menawarkan konsep, promosi, kemasan, cita rasa yang ditawarkan, serta pemilihan nama untuk oleh oleh kekinian mereka. Dari 30 toko kue selebriti yang paling banyak pengikutnya pada Instagram adalah Bandung Makuta milik Laudya Chyntia Bella dengan 368.000 follower (Instagram, 2017). Selebriti menjadi pemilik sekaligus endoser usaha ini, menurut Belh and Belch, adalah seseorang atau kelompok yang mengkomunikasikan pesan produk atau jasa sehingga produk atau jasa tersebut dikenal masyarakat (Belch, Kerr, \& Powell, 2008).Hasil penelitian sebelumnya yang relevan pertama, menunjukkan bahwa perannya komunikasi pemasaran perusahaan secara sosial media mempengaruhi kesadaran pengguna media sosial pada merek perusahaan (Tarigan \& Tritama, 2016). Penelitian kedua, bahwa media sosial hanya $20 \%$ digunakan serius untuk bisnis, selebihnya social networking bisnis menunjukan hanya membantu menganalisis target, meningkatkan kepercayaan produk di kalangan konsumen dan juga meningkatkan keuntungan dan penjualan (Farooq \& Jan, 2012). Penelitian ketiga, juga menyatakan bahwa komunikasi media sosial yang dibuat oleh perusahaan dan buatan pengguna secara positif mempengaruhi pola pikir konsumen dan evaluasi merek di mana kesadaran merek masuk pada bagian evaluasi merek (Schivinski, 2013). Untuk penelitian keempat menggunakan media sosial menujukkan peserta didik dengan adanya teknologi media sosial lebih mudah dalam belajar (Baruah, 2012). Penelitian sebelumnya yang kelima menunjukkan kausalitas variabel Communitization terhadap variabel Ekuitas Merek (Yonaldi \& Yanti, 2014). Pada penelitian sebelumnya yang keenam hasil hasil penelitian menunjukkan Teknik marketing menggunakan media sosial Instagram membuktikan paling sukses perhitungan dilihat dari banyaknya menerima pengikut, pengkuan akan mereka yang lebih luas melalui pembicaraan dari mulut ke mulut, dan meningkatkan penjualan (Ha, 2015). Untuk penelitian ketujuh menghasilkan Media Sosial Twitter mempunyai kausalitas sebesar $70 \%$ antara terhadap kesadaran merek produk buffalo pada PT ECS Indo Jaya (Orcatti, 2012). Selanjutnya untuk penelitian relevan kedelapan penelitian penelitian ke delapan yang menjadi referensi penelitian ini menunjukkan pemasaran menggunakan Media Sosial Twitter dan terus meningkatkan keterlibatan dan pemberdayaan konsumen untuk meningkatkan customer engagemnet yang tentunya akan menguntungkan pihak 
IndiHome Triple Play dalam menjalin hubungan dengan pelanggan dan menarik pelanggan potensial (Armas \& Abdullah, 2015) Penelitian kesembilan menunjukkan bahwa konsumen endorser memiliki efek positif dalam menciptakan efektivitas di iklan media sosial, yang mempengaruhi konsumen "Sikap dan Perilaku". Beberapa karakteristik dari endorser yang bisa dipercaya dan menarik dapat menciptakan kesadaran produk, minat dan keinginan dalam konsumen mengarah pada niat untuk membeli. Namun, Keahlian endorser konsumen hanya bisa menciptakan Kesadaran tapi tidak bisa menimbulkan minat, keinginan dan niat untuk membeli (Nguyen, Preedanorawut, \& Clarie, 2011).Terakhir penelitian relevan kesepuluh Analisis Pengaruh Daya Tarik Iklan dan Selebriti Endorser Pada Promo Adaaqua Terhadap Minat Beli AMDK Merek AQUA dengan Citra Merek Sebagai Variabel Intervening (Studi Kasus Pada Mahasiswa S1 di Jawa Tengah Dan DIY) vol.5 No.3 2016 pada jurnal online Universitas Diponogoro. Hasil menunjukkan bahwa daya tarik iklan berpengaruh positif dan signifikan terhadap Brand Image, Celebrity Endorser memiliki efek positif terhadap Brand Image, Daya Tarik Iklan telah positif untuk membeli niat, Celebrity Endorser dan Brand Image miliki positif dan signifikan terhadap niat beli.

Dari pemaparan di atas peneltian ini menguji Komunikasi Pemasaran Sosial Media Instagram pada Konsumen Toko Kue Selebriti Bandung Makuta (@Bandungmakuta) Terhadap kesadaran merek, Bandung Makuta (@Bandungmakuta) menggunakan Instagram sebagai alat komunikasi pemasarannya. Tujuan dari penelitian ini
Menguji korelasi Komunikasi Pemasaran Sosial Media Instagram pada konsumen Toko Kue Selebriti Bandung Makuta (@Bandungmakuta) pada kesadaran merek. Hasil penelitian ini akan merekomendasikan manajemen perusahaan atau organisasi untuk meningkatkan strategi pemasaran khususnya pada media sosial.

\section{Kerangka Pemikiran}

\subsection{Komunikasi Pemasaran Media Sosial}

Suatu konsep perencanaan komunikasi pemasaran yang mengakui nilai tambah dari satu rencana komprehensif yang mengevaluasi peran strategis dari berbagai disiplin komunikasi - misalnya, iklan umum, respon langsung, promosi penjualan, dan hubungan masyarakat - dan menggabungkan berbagai disiplin tersebut guna memberikan kejelasan, konsistensi, serta dampak komunikasi yang maksimal. Social media sebagai sebuah bagian dari aplikasi berbasis internet yang membangun ideologi dan pencanang teknologi web 2.0 yang mengizinkan untuk membentuk dan merubah isi (Kaplan \& Haenlein, 2012). Untuk Social media marketing adalah sebagai sebuah proses yang memberdayakan individu dan perusahaan untuk mempromosikan website mereka, produk atau layanan online dan melalui saluran sosial untuk berkomunikasi dengan sebuah komunitas yang jauh lebih besar yang tidak mungkin tersedia melalui saluran periklanan tradisional(Drury, 2008). Chris Heurer dalam (Solis \& Kutcher, 2011) pendiri social media club dan inovator media baru, membahas $4 \mathrm{C}$ dalam pengoperasian media sosial dari segi; Konteks, Komunikasi, Kolaborasi, dan Koneksi. 


\subsection{Selebriti Endoser}

Selebriti adalah sosok yang menikmati pengakuan publik atau kelompok sosial masyarakat tertentu karena sejumlah karaktersitik yang atraktif, gaya hidup luar biasa atau skill tertentu yang dapat dilihat secara kasat mata serta sejumlah karakter yang tidak kasat mata (Gony, 2007) Endorser sering juga disebut sebagai direct source (sumber langsung) yaitu seorang pembicara yang mengantarkan sebuah pesan dan atau memperagakan sebuah produk atau jasa (Belch et al., 2008). Maka keahlian yang dimiliki selebriti dengan merek produk yang diiklankan haruslah relevan (Drewniany \& Jewler, 2007). Dalam buku Advertising Communication and Promotion Management tulisan John Ressister dan Larry Perry disebutkan bahwa selebriti dapat digunakan oleh pemasar untuk melakukan boosting terhadap satu atau lebih komunikasi yang akan dilakukan. Itu artinya bahwa selebriti diharapkan nantinya dapat membantu Brand Awarenes, Brand Recognition, Brand Recall, dan meningkat pada brand 21 purchase. Hal ini juga ditegaskan oleh Agrawal dan Kamakura dalam Jurnal Marketing tahun 1995 bertajuk The Economic worth of celebrity endorser; an event study analysis, bahwa konsumen lebih memilih barang atau jasa yang di-endor oleh selebriti dibanding tidak (Erdogan, Baker, \& Tagg, 2001). tiga komponen yang mempengaruhi kredibilitas selebritis sebagai endoser yaitu ketertarikan

(attractiveness), keterpercayaan (trustworthiness), keahlian (expertise).

\subsection{Brand Awareness}

Brand Awareness adalah kesanggupan seorang calon pembeli untuk mengenali, mengingat kembali suatu merek sebagai bagian dari suatu kategori produk tertentu. Menurut (Rangkuti, 2004), mendefinisikan kesadaran merek merupakan kemampuan seorang pelanggan untuk mengingat suatu merek tertentu atau iklan tertentu secara spontan atau setelah dirangsang dengan kata-kata kunci. Dikutip dari jurnal Bisnis (Budi, Elza, \& Safan, 2006) Strategi yang sukses dari kesadaran mere $k$ harus dapat menjelaskan keunikan dari merek itu sendiri dan menjadikannya berbeda dari kompetitor yang ada. Contoh: jika konsumen tidak mengetahui apa pun tentang suatu perusahaan, mereka tidak akan membeli sesuatu dari perusahaan tersebut. Untuk itulah satu dari tujuan utama setiap bisnis seharusnya ialah untuk membangun kesadaran merek karena keinginan membeli konsumen sangat dipengaruhi dari rekomendasi pengalaman langsung. kesadaran merek adalah sebuah kemampuan dari seorang pembeli potensial untuk mengenali atau memanggil ulang (mengingat) bahwa sebuah merek adalah bagian dari sebuah kategori produk tertentu(Aaker, 1991). kesadaran merek sendiri mempunyai empat tingkatan untuk dapat membentuk suatu nilai didalam benak calon konsumen. Menurut Aaker dan Simamora dalam (Haryanto, 2009) empat tingkatan tersebut adalah: pertama Tidak menyadari merek (Brand Unaware) kedua Pengenalan merek (Brand Recognition), ketiga, Pengingatan kembali merek (Brand Recall), keempat puncak pikiran (Top of Mind)

\subsection{Penelitian Sebelumnya}

Penelitian ini yang dilakukan oleh (Tarigan \& Tritama, 2016) mendukung penelitian ini, menunjukkan bahwa perannya komunikasi pemasaran perusahaan secara sosial media mempengaruhi kesadaran pengguna media 
sosial pada merek perusahaan. Penelitian yang dilakukan oleh (Farooq \& Jan, 2012), bahwa media sosial hanya $20 \%$ digunakan serius untuk bisnis, selebihnya social networking bisnis menunjukan hanya membantu menganalisis target, meningkatkan kepercayaan produk di kalangan konsumen dan juga meningkatkan keuntungan dan penjualan. Penelitian oleh (Schivinski, 2013), juga menyatakan bahwa komunikasi media sosial yang dibuat oleh perusahaan dan buatan pengguna secara positif mempengaruhi pola pikir konsumen dan evaluasi merek di mana kesadaran merek masuk pada bagian evaluasi merek. Untuk penelitian keempat oleh (Baruah, 2012) menggunakan media sosial menujukkan peserta didik dengan adanya teknologi media sosial lebih mudah dalam belajar. Penelitian oleh (Yonaldi \& Yanti, 2014), menunjukkan kausalitas variabel Communitization terhadap variabel Ekuitas Merek. Pada penelitian sebelumnya yang mendukung penelitian ini dari (Ha, 2015), yang keenam hasil hasil penelitian menunjukkan Teknik marketing menggunakan media sosial Instagram membuktikan paling sukses perhitungan dilihat dari banyaknya menerima pengikut, pengkuan akan mereka yang lebih luas melalui pembicaraan dari mulut ke mulut, dan meningkatkan penjualan. Penelitian oleh (Orcatti, 2012) menghasilkan Media Sosial Twitter mempunyai kausalitas sebesar $70 \%$ antara terhadap kesadaran merek produk buffalo pada PT ECS Indo Jaya. Selanjutnya penelitian oleh (Armas \& Abdullah, 2015) yang menjadi referensi penelitian ini menunjukkan pemasaran menggunakan Media Sosial Twitter dan terus meningkatkan keterlibatan dan pemberdayaan konsumen untuk meningkatkan customer engagemnet yang tentunya akan menguntungkan pihak IndiHome Triple Play dalam menjalin hubungan dengan pelanggan dan menarik pelanggan potensial. Penelitian oleh (Nhung, 2011) menunjukkan bahwa konsumen endorser memiliki efek positif dalam menciptakan efektivitas di iklan media sosial, yang mempengaruhi konsumen "sikap dan perilaku". Beberapa karakteristik dari endorser yang bisa dipercaya dan menarik dapat menciptakan kesadaran produk, minat dan keinginan dalam konsumen mengarah pada niat untuk membeli. Namun, Keahlian endorser konsumen hanya bisa menciptakan Kesadaran tapi tidak bisa menimbulkan minat, keinginan dan niat untuk membeli. Terakhir penelitian relevan (Anggi \& Soesanto, 2016) Analisis Pengaruh Daya Tarik Iklan dan Selebriti Endorser Pada Promo Ada aqua Terhadap Minat Beli AMDK Merek AQUA dengan Citra Merek Sebagai Variabel Intervening (Studi Kasus Pada Mahasiswa S1 di Jawa Tengah dan DIY) vol.5 No.3 2016 pada jurnal online Universitas Diponogoro. Hasil menunjukkan bahwa daya tarik iklan berpengaruh positif dan signifikan terhadap brand image, celebrity endorser memiliki efek positif terhadap brand image, daya tarik iklan telah positif untuk membeli niat, celebrity endorser dan brand image miliki positif dan signifikan terhadap niat beli.

\section{Metode Penelitian}

Penelitian ini menggunakan metodologi dan pendekatan kuantitatif eksploratif. Metode yang diusung dalam penelitian ini adalah metode survei. Penelitian eksploratif bertujuan untuk menguji teori atau hipotesis untuk memperkuat atau bahkan menolak teori atau hipotesis dari penelitian yang sudah 
ada. Penyelidikan Penelitian memiliki sifat dasar dan bertujuan untuk mendapatkan eksplorasi, informasi dan data tentang halhal yang ada belum diketahui. Karena memiliki sifat dasar, Studi ini disebut eksplorasi. Beberapa pertanyaannya adalah disiapkan sebagai panduan untuk mendapatkan data primer dalam bentuk penjelasan dan informasi, sebagai data awal wajib. Tujuan penelitian penjelasan adalah untuk menguji sebuah penelitian dengan maksud untuk membenarkan atau memperkuat dan menentukan sifat hubungan antara satu atau lebih gejala atau variabel dependen satu atau lebih variabel independen.

Paradigma penelitian yang digunakan sesuai dengan metode penelitian kuantitatif, yaitu paradigma positivistik. Paradigma positivistik dinyatakan sebagai paradigma tradisional, eksperimental, atau paradigma empirisistis yang dikembangkan oleh para ahli sosiologi. Positivisme menggambarkan pendekatan baru terhadap pengetahuan.

Untuk menghindari ruang lingkup yang terlalu luas, maka memfokuskan Penelitian yang akan diteliti, yaitu untuk mengetahui sejauh mana pengaruh antara Komunikasi Pemasaran Media Sosial Instagram pada toko kue milik Laudya Chyntia Bella seorang Selebriti sekaligus Endoser bernama Bandung Makuta terhadap kesadaran merek.

Pada penelitian ini menunjukkan Gambar 1. Variabel Independen model di atas diadopsi dari Penelitian sebelumnya namun telah dilakukan modifikasi dan penambahan variabel baru. Variabel Media sosial Instagram (X1) memiliki nilai Cronbach alpha 0.744. Untuk variabel Selebriti Endoser (X2) memiliki nilai Cronbach alpha 0.826, dan untuk Varibel dependen Kesadaran Merek (Y) memiliki nilai Cronbach alpha 0.814 .

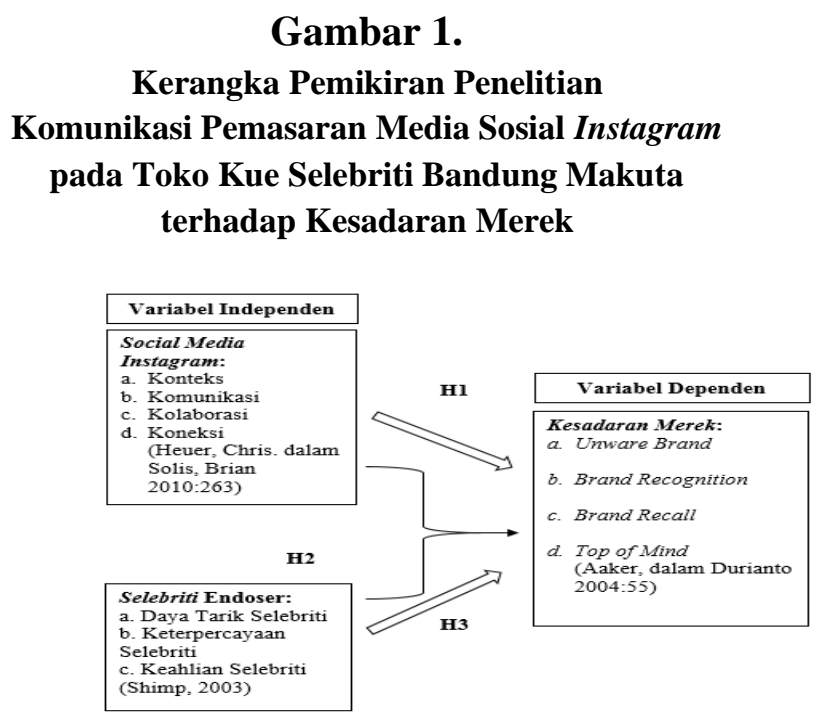

Berdasarkan penjelasan di atas, hal itu menunjukkan bahwa beberapa Variabel yang digunakan diadopsi dari penelitian sebelumnya namun Ada juga variabel yang dimodifikasi agar bisa untuk berkontribusi terhadap penelitian yang ada atau yang akan datang. Jadi, ini penelitian dapat dilanjutkan ke penelitian yang lebih dalam. Hipotesis untuk dilakukan pengujian, yaitu: $\mathrm{H}_{0}$ : Komunikasi Pemasaran Media Sosial Instagram tidak memiliki korelasi terhadap Kesadaran Merek.

$\mathrm{H}_{1}$ : Komunikasi Pemasaran Media Sosial Instagram memiliki korelasi terhadap Kesadaran Merek.

$\mathrm{H}_{0}$ : Selebriti Endoser tidak memiliki korelasi terhadap Kesadaran Merek

$\mathrm{H}_{2}$ : Selebriti Endoser memiliki korelasi terhadap Kesadaran Merek

$\mathrm{H}_{0}$ : Komunikasi Pemasaran Media Sosial Instagram melalui Selebriti Endoser tidak memiliki korelasi terhadap Kesadaran Merek

$\mathrm{H}_{3}$ : Komunikasi Pemasaran Media Sosial Instagram melalui Selebriti Endoser memiliki korelasi terhadap Kesadaran Merek

Populasi dalam penelitian ini sebesar 368.000 followers Instagram Toko Kue Selebriti Bandung Makuta. 
Pengambilan sampel dalam penelitian ini menggunakan teknik simple random sampling.

Teknik simple random sampling memungkinkan setiap unit sampling sebagai unsur populasi memperoleh peluang yang sama untuk menjadi sampel, sampel dari keseluruhan jumlah populasi akan peneliti ambil dengan menggunakan rumus Slovin dengan presisi 5\% dan tingkat kepercayaan $95 \%$. Berdasarkan penggunaan sampel proporsional maka diperoleh 399 responden.

Data primer merupakan data yang langsung diperoleh dari sumber data pertama di lokasi penelitian atau objek penelitian. Data primer dapat berbentuk opini subjek secara individual atau kelompok, dan hasil observasi terhadap karakteristik benda (fisik), kejadian kegiatan dan hasil suatu pengujian tertentu (Hasan, 2002). Data primer diperoleh peneliti dan penyebaran kuesioner yang berisi pertanyaan dan peryataan yang berkaitan dengan Instagram sebagai Komunikasi Pemasaran Sosial Media Instagram pada Konsumen Toko Kue Selebriti Bandung Makuta (@Bandungmakuta) Terhadap Kesadaran Merek. Kuesioner akan disebar dengan sistem online menggunakan google docs.

Data pendukung penulis yang didapat dari bacaan-bacaan atau laporanlaporan peneliti terdahulu biasanya berupa arsip kepustakaan. Data sekunder ini disebut juga data tersedia. Dalam penelitian ini berupa data-data referensi dari pustaka dan buku pendukung lainnya (Hasan, 2002)

Menurut (Silalahi, 2003) pengertian operasional merupakan suatu unsur penelitian yang memberitahukan bagaimana caranya mengukur suatu variabel. Dalam penelitian ini digunakan beberapa variabel untuk mengetahui pengaruh variabel Independen Komunikasi Pemasaran Media Sosial Instagram, Selebriti Endoser, dan variabel dependen Kesadaran Merek.

Variabel Independen media sosial Instagram, Chris Heurer dalam (Solis \& Kutcher, 2011) pendiri social media club dan inovator media baru, membahas 4C dalam pengoperasian media sosial, yaitu: (1) Konteks: Media Sosial membingkai cerita. Cara penyampaian pesan kepada khalayak dalam rangka menarik perhatian, informasi, promosi, dan sebagainya; (2) Komunikasi: Media Sosial digunakan untuk berkomunikasi dan proses penyampaian pesan yang dilakukan melalui media sosial dapat memberikan pemahaman serta menimbulkan tanggapan atau umpan balik; (3) Kolaborasi: Media Sosial dapat mendorong kotribusi dan umpan balik sehingga dapat membuat komunikasi lebih efektif dan efisien dan (3) Koneksi: melalui media sosial dapat memilihara hubungan yang telah dibangun untuk memberikan kenyamanan dalam hubungan yang telah dibangun.

\section{Variabel Selebriti Endoser yaitu (1)}

Daya Tarik Selebriti, Yang dimaksud dengan daya tarik selebriti disini adalah karakteristik fisik atau yang nampak dari selebriti (Heruwati, 2010). Indikatorindikator daya tarik selebriti yang digunakan dalam penelitian ini mengacu pada penelitian (Heruwati, 2010) antara lain: Menarik (attractive), Berkelas (classy), Cantik (beautiful), Luwes (elegant), Seksi (sexy); (2) Keterpercayaan Selebriti, Yang dimaksud dengan kepercayaan selebriti adalah pandangan konsumen tentang pribadi selebriti dalam (Heruwati, 2010). Indikator-indikator keterpercayaan selebriti yang digunakan 
dalam penelitian ini mengacu pada penelitian (Heruwati, 2010) antara lain: Dapat di jadikan pedoman (dependable), Jujur (honest), Dapat diandalkan (reliable), Tulus (sincere), Dapat di percaya (trustworthy), (3) Keahlian Selebriti, Yang dimaksud dengan keahlian disini adalah pengetahuan selebriti tentang produk yang diendors-nya (Shimp 2003 dalam (Heruwati, 2010). Indikator-indikator keahlian selebriti yang digunakan dalam penelitian ini mengacu pada penelitian (Heruwati, 2010) antara lain: Ahli (expert), Berpengalaman

Berpengetahuan (experience), Memenuhi syarat (qualified), Terlatih (skilled).

Variabel Dependen Kesadaran Merek yaitu (1) Puncak pikiran (Top of Mind) Yang dimaksud dengan Top of Mind adalah merek yang pertama kali diingat oleh responden atau pertama kali disebut ketika responden ditanya tentang suatu produk tertentu. Top of Mind menggunakan single respond question yang artinya responden hanya boleh memberikan satu jawaban untuk pertanyaan mengenai hal ini; (2) Pengingatan kembali merek (Brand Recall) Brand recall adalah pengingat kembali merek yang dicerminkan dengan merek lain yang diingat oleh responden setelah responden menyebutkan merek yang pertama. Brand recall menggunakan multi respond questions yang artinya memberikan jawaban tanpa dibantu; (3) Pengenalan merek (Brand recognition) Brand recognition adalah pengenalan merek yaitu tingkat kesadaran responden terhadap suatu merek yaitu tingkat kesadaran responden terhadap suatu merek diukur dengan diberikan bantuan seperti ciri-ciri suatu produk; dan (3) Tidak menyadari merek (Unware of brand) Merupakan tingkat yang paling rendah dari piramida kesadaran merek dimana konsumen tidak menyadari akan adanya suatu merek. 
Table 1 Operasionalisasi Konsep

\begin{tabular}{|c|c|c|c|c|}
\hline Variabel & Indikator & Deskriptor & Skala Pengukuran & Penilaian \\
\hline $\begin{array}{l}\text { Variabel Independen } \\
\text { "Komunikasi } \\
\text { Pemasaran Media } \\
\text { Sosial Instagram } \\
\text { Chris Heurer dalam } \\
\text { (Solis \& Kutcher, } \\
2011)\end{array}$ & $\begin{array}{l}\text { Konteks } \\
\text { Komunikasi } \\
\text { Kolaborasi } \\
\text { Koneksi }\end{array}$ & $\begin{array}{l}\text { Cara penyampaian pesan kepada khalayak dalam } \\
\text { rangka menarik perhatian, informasi, promosi, dan } \\
\text { sebagainya. Proses penyampaian pesan yang } \\
\text { berlangsung, informasi yang disampaikan bisa } \\
\text { memberikan pemahaman dan tanggapan atau umpan } \\
\text { balik dalam komunikasi antara administrator social } \\
\text { media dan pengguna. Media social mendorong } \\
\text { kontribusi dan umpan balik Pemiliharaan hubungan } \\
\text { yang telah dibangun untuk memberikan kenyamanan } \\
\text { dalam hubungan yang telah dibangun }\end{array}$ & Skala Likert & $\begin{array}{ll}\text { 1. } & \text { Sangat setuju } \\
\text { 2. } & \text { Setuju } \\
\text { 3. } & \text { Kurang Setuju } \\
\text { 4. } & \text { Tidak setuju } \\
\text { 5. } & \text { Sangat tidak } \\
& \text { setuju }\end{array}$ \\
\hline $\begin{array}{l}\text { Variabel Selebriti } \\
\text { Endoser (Shimp } 2003 \\
\text { dalam Heruwati 2010) }\end{array}$ & $\begin{array}{l}\text { 1. Daya Tarik Selebriti } \\
\text { 2. Keterpercayaan } \\
\text { Selebriti } \\
\text { 3. Keahlian Selebriti }\end{array}$ & $\begin{array}{l}\text { Karakteristik fisik atau yang nampak dari selebriti : } \\
\text { A. Menarik (attractive) b. Berkelas (classy) } \\
\text { C. Cantik (beautiful) } \\
\text { D. Luwes (elegant) } \\
\text { E. Seksi (sexy) } \\
\text { Pandangan konsumen tentang pribadi selebriti: } \\
\text { A. Dapat di jadikan pedoman (dependable) } \\
\text { B. Jujur (honest) } \\
\text { C. Dapat diandalkan (reliable) } \\
\text { D. Tulus (sincere) } \\
\text { E. Dapat di percaya (trustworthy) } \\
\text { Pengetahuan selebriti tentang produk yang diendors- } \\
\text { nya: } \\
\text { A. Ahli (expert) } \\
\text { B. Berpengalaman (experience) } \\
\text { C. Berpengetahuan (knowledgeable) } \\
\text { D. Memenuhi syarat (qualified) } \\
\text { E. Terlatih (skilled) }\end{array}$ & Skala Likert & $\begin{array}{ll}\text { 1. } & \text { Sangat setuju } \\
\text { 2. } & \text { Setuju } \\
\text { 3. } & \text { Kurang Setuju } \\
\text { 4. } & \text { Tidak setuju } \\
\text { 5. } & \text { Sangat tidak } \\
& \text { setuju }\end{array}$ \\
\hline $\begin{array}{l}\text { Variabel Dependen } \\
\text { Kesadaran Merek } \\
\text { (Durianto, et all, } \\
\text { 2004:55) }\end{array}$ & $\begin{array}{ll}\text { 1. } & \text { Puncak pikiran (Top of } \\
\text { Mind) } \\
\text { 2. Pengingatan kembali } \\
\text { merek (Brand Recall) } \\
\text { 3. Pengenalan merek } \\
\text { (Brand recognition) } \\
\text { 4. Tidak menyadari merek } \\
\text { (Unware of brand) }\end{array}$ & $\begin{array}{l}\text { Merek yang pertama kali diingat oleh responden atau } \\
\text { pertama kali disebut ketika responden ditanya tentang } \\
\text { suatu produk tertentu } \\
\text { Merek lain yang diingat oleh responden setelah } \\
\text { responden menyebutkan merek yang pertama } \\
\text { Tingkat kesadaran responden terhadap suatu merek } \\
\text { diukur dengan diberikan bantuan seperti ciri-ciri suatu } \\
\text { produk. } \\
\text { Konsumen tidak menyadari akan adanya suatu merek. }\end{array}$ & Skala Likert & $\begin{array}{ll}\text { 1. } & \text { Sangat setuju } \\
\text { 2. } & \text { Setuju } \\
\text { 3. } & \text { Kurang Setuju } \\
\text { 4. } & \text { Tidak setuju } \\
\text { 5. } & \text { Sangat tidak } \\
& \text { setuju }\end{array}$ \\
\hline
\end{tabular}




\section{Hasil Dan Pembahasan}

Berdasarkan uji validitas dan reliabilitas dari setiap variabel didapatkan model kuesioner dikatakan valid reliabel dengan nilai $\mathrm{r}_{\text {hitung }}$ lebih besar dari $\mathrm{r}_{\text {tabel }}$ 0.113 . Nilai cronbach alpha variabel media sosial didapatkan 0.745 , selebriti endoser sebesar 0.681, dan kesadaran merek 0.696.

Table 2 Demografi Responden

\begin{tabular}{|l|l|l|l|}
\hline No & $\begin{array}{l}\text { Karakteristik } \\
\text { Demografi }\end{array}$ & Kategori & $\begin{array}{l}\text { Frekuensi } \\
\text { (Orang) }\end{array}$ \\
\hline 1. & Jenis Kelamin & $\begin{array}{l}\text { Wanita } \\
\text { Pria }\end{array}$ & $\begin{array}{l}249 \\
150\end{array}$ \\
\hline 2. & Pekerjaan & Pelajar & 84 \\
& & Mahasiswa & 141 \\
& & Wiraswasta & 41 \\
& & Pegawai & 116 \\
& & Swasta & 17 \\
& & Pegawai & \\
\hline 3. & Negeri & \\
& Durasi (follow & <3 Bulan & 123 \\
& Instagram & 3-6 Bulan & 192 \\
& @ Bandung & $>$ Bulan & 84 \\
& Makuta) & & \\
\hline
\end{tabular}

Uji t dilakukan untuk menunjukan korelasi variabel independent dalam menjelaskan variabel dependen dengan kriteria nilai $\mathrm{t}$ hitung $\geq \mathrm{t}$ tabel atau nilai sig $\leq 0,05$. Dalam penelitian ini menunjukan bahwa nilai t hitung korelasi variabel media sosial terhadap variabel kesadaran merek mempunyai t hitung $6.253>\mathrm{t}$ table 1.660 dengan nilai sig $0,000 \leq 0,05$.

Uji t kedua dalam penelitian ini menunjukan bahwa nilai t hitung korelasi variabel selebriti endoser terhadap variabel kesadaran merek mempunyai $\mathrm{t}$ hitung $12.156 \geq \mathrm{t}$ table 1.660 dengan nilai sig $0,000 \leq 0,05$.

Uji $\mathrm{F}$ dilakukan untuk menunjukan apakah semua variabel independen yang dimasukan dalam model penelitian memiliki korelasi secara bersama-sama terhadap variabel dependen. Pada penelitian ini hasil uji $\mathrm{F}$ mendapatkan hasil F hitung sebesar 136.126 dari F tabel 2.60 dengan tingkat signifikan 0,000. Dari hasil yang didapat, maka dapat disimpulkan bahwa variabel media sosial secara simultan bersama selebriti endoser cukup berkorelasi terhadap kesadaran merek yaitu $41 \%$.

Table 3 Uji T

Coefficients $^{\mathrm{a}}$

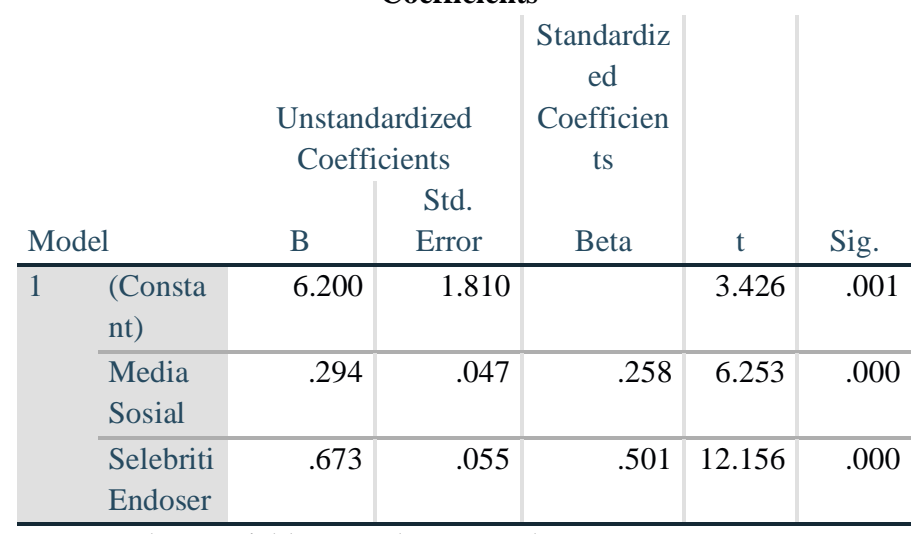

a. Dependent Variable: Kesadaran Merek

Kesimpulan Hipotesis setelah pengujian pengujian, yaitu:

$\mathrm{H}_{1}$ : Komunikasi Pemasaran Media Sosial Instagram memiliki korelasi terhadap Kesadaran Merek.

Hipotesis pertama menunjukkan adanya korelasi positif dari variabel Media sosial terhadap. Kesimpulan Hipotesis setelah pengujian pengujian, yaitu:

$\mathrm{H}_{1}$ : Komunikasi Pemasaran Media Sosial Instagram memiliki korelasi terhadap Kesadaran Merek.

Hipotesis pertama menunjukkan adanya korelasi positif dari variabel Media sosial terhadap Kesadaran Merek. $\mathrm{H}_{1}$ diterima dengan tingkat nilai sig 0.000 dimana nilai signifikansi tersebut $<0.05$.

$\mathrm{H}_{2}$ : Selebriti Endoser memiliki korelasi terhadap Kesadaran Merek

Hipotesis kedua menunjukkan adanya korelasi positif dari variabel Selebriti Endoser terhadap Kesadaran Merek. $\mathrm{H}_{2}$ diterima dengan tingkat nilai sig 0.000 dimana nilai signifikansi tersebut $<0.05$. 
$\mathrm{H}_{3}$ : Komunikasi Pemasaran Media Sosial Instagram melalui Selebriti Endoser memiliki korelasi terhadap Kesadaran Merek. Hipotesis ketiga menunjukkan adanya korelasi positif secara simultan dari variabel Media sosial, Selebriti Endoser terhadap Kesadaran Merek. $\mathbf{H}_{3}$ diterima dengan tingkat nilai sig 0.000 dimana nilai signifikansi tersebut $<0.05$.

\begin{tabular}{|c|c|c|c|c|c|c|}
\hline \multicolumn{7}{|c|}{$\begin{array}{c}\text { Table 4. Uji F } \\
\text { ANOVA }^{\mathrm{a}}\end{array}$} \\
\hline \multicolumn{2}{|c|}{ Model } & $\begin{array}{l}\text { Sum of } \\
\text { Squares }\end{array}$ & $\mathrm{df}$ & $\begin{array}{l}\text { Mean } \\
\text { Square }\end{array}$ & $\mathrm{F}$ & Sig. \\
\hline 1 & $\begin{array}{l}\text { Regressi } \\
\text { on }\end{array}$ & 1772.276 & 2 & 886.138 & $\begin{array}{r}136.1 \\
26\end{array}$ & $.000^{\mathrm{b}}$ \\
\hline & Residual & 2577.844 & 396 & 6.510 & & \\
\hline & Total & 4350.120 & 398 & & & \\
\hline
\end{tabular}

a. Dependent Variable: Brand

b. Predictors: (Constant), Seleb, Medsos

\section{Penutup}

Setelah dilakukan analisis dalam penelitian yang berjudul "Komunikasi Pemasaran Sosial Media Instagram Pada Toko Kue Selebriti Bandung Makuta (@Bandungmakuta) Terhadap Kesadaran Merek", maka dapat disimpulkan bahwa berdasarkan analisis regresi linier berganda, diketahui bahwa media sosial Instagram memiliki korelasi positif signifikan terhadap kesadaran merek. Hal ini berarti bahwa semakin tinggi pengkomunikasian produk atau perusahaan melalui sosial media maka semakin tinggi juga kesadaran merek para follower Instagram itu sendiri.

Berdasarkan analisis regresi linier berganda, diketahui bahwa selebriti endoser toko kue Bandung Makuta memiliki korelasi positif signifikan terhadap kesadaran merek. Hal ini berarti bahwa semakin kredibilitas seorang endoser baik melalui sosial media maka semakin tinggi juga kesadaran merek para follower Instagram itu sendiri.
Berdasarkan analisis regresi linier berganda, diketahui bahwa media sosial Instagram, selebriti endoser memiliki korelasi positif signifikan terhadap kesadaran merek. Hal ini berarti bahwa semakin tinggi pengkomunikasian produk atau perusahaan melalui sosial media oleh selebriti endoser yang memiliki tingkat kredibilitas baik maka semakin tinggi juga kesadaran merek para follower Instagram itu sendiri.

Banyak perusahaan atau organisasi yang memanfaatkan media sosial sebagai sarana mempromosikan produknya dalam upaya memenangkan persaingan di tengah banyaknya kompetitor produk sejenis, salah satu perusahaan yang memanfaatkan media sosial Instagram tersebut adalah toko kue Bandung Makuta yang memiliki selebriti endoser Laudya Cynthia Bella.

Dari beberapa penelitian yang pernah dilakukan, media sosial berkorelasi tinggi dengan kesadaran merek bahwa apa yang disampaikan pada media sosial dapat meningkatkan Top of Mind para follower. Lalu penelitian terdahulu lainnya menunjukkan selebriti endoser berkorelasi terhadap citra merek dan minat beli. Namun pada penelitian ini bermodel modifikasi, varibel yang digunakan dengan acuan penelitian terdahulu dibuktikan berkorelasi antara media sosial, selebriti endoser terhadap kesadaran merek. Media sosial, selebriti endoser berkorelasi terhadap kesadaran merek. Media sosial dapat membangun korelasi dengan kesadaran merek melalui konteks promosi, cara berkomunikasi, kolaborasi dengan follower, serta koneksi membuat kesadaran merek follower akan toko kue Bandung Makuta semakin meningkat. Kemudian dari selebriti endoser melalui daya tarik selebriti, keterpercayaan selebriti, dan 
keahlian selebriti membuat kesadaran merek follower akan toko kue Bandung Makuta. Selebriti endorser memberikan pengaruh baik secara langsung maupun tidak langsung terhadap kesadaran merek Follower Pada Toko Kue Bandung Makuta. Semakin menarik, kredibel, dan berkharisma selebriti yang dijadikan endorser toko kue Bandung Makuta, maka konsumen semakin sadar atas produk tersebut.

\section{DAFTAR PUSTAKA}

Aaker, D. A. (1991). Inova Consultoria De Gestão E Inovação Estratégica Ltda Todos Os Direitos Reservados. In Inova Consultoria De Gestão E Inovação Estratégica Ltda. Free Press.

IBelch, G., Belch, G. E., Belch, M. A., Kerr, G., \& Powell, I. (2008). Advertising and Promotion: An Integrated Marketing Communications Perspective. McGraw-Hill Australia.

Drewniany, B., \& Jewler, A. (2007). Creative Strategy in Advertising. Cengage Learning.

Hasan, M. I. (2002). Pokok-Pokok Materi Metodologi Penelitian dan Aplikasinya.

Heruwati, E. (2010). Analisis Pengaruh Daya Tarik, Kredibilitas, dan Keahlian Celebrity Endoser Terhadap Keputusan Pembelian Sepeda Motor Yamaha Mio (Studi pada konsumen PT Harpindo Jaya Jl. Dr. Cipto No. 61 Semarang). 127.

KKartajaya, H. (2013). CONNECT Surfing New Wave Marketing. Gramedia Pustaka Utama. Nguyen, P. N., Preedanorawut, S., \& Clarie, T. X. H. (2011). Effectiveness of Consumer Endorser in Social
Media Advertisement Impact on consumers "attitudes and behaviors. Orcatti. (2012). Pengaruh Peran Media Sosial Twitter Terhadap Brand Awareness Produk Buffalo (Studi Kasus : PT ECS Indo Jaya). Rangkuti, Freddy, (2004). The Power of Brand, Jakarta : Gramedia Pustaka Utama

Solis, B., \& Kutcher, A. (2011). Engage!, Revised and Updated: The Complete Guide for Brands and Businesses to Build, Cultivate, and Measure Success in the New Web. Wiley. Silalahi, Ulbert.(2003). Studi Tentang Ilmu Administrasi. Bandung : Sinar Baru Agiesindo

\section{Jurnal}

Anggi, V. F., \& Soesanto, H. (2016). Analisis Pengaruh Daya Tarik Iklan dan Selebriti Endoser Pada Promo AdaAQUA Terhadap Minat Beli AMDK Merek AQUA Dengan Citra Merek Sebagai Variabel Intervening (Studi Kasus pada Mahasiswa S1 di Jawa Tengah dan DIY). Jurnal Manajemen, 5(3), 15.

Armas, R., \& Abdullah. (2015). The Effect of Social Media Twitter Toward Brand Awareness of Indihome Triple Play. Jurnal Manajemen, 2(3), 8.

Baruah, T. D. (2012). Effectiveness of Social Media as a tool of communication and its potential for technology enabled connections : A micro-level study. International Journal of Scientific and Research Publications, 2(5), 10.

Budi, S; Elza, M.S, \& M.S, Safan. (2006). Analisis Brand awareness minimarket di Jakarta. E- Journal Bisnis Strategi Oertasih Efesiensi Drury, G. (2008). Opinion piece: Social 
media: Should marketers engage and how can it be done effectively?

Journal of Direct, Data and Digital Marketing Practice, 9(3), 274-277. https://doi.org/10.1057/palgrave.ddd mp.4350096

Erdogan, B. Z., Baker, M. J., \& Tagg, S. (2001). Selecting celebrity endorsers: The practitioner's perspective.

Journal of Advertising Research, 41(3), 11.

Farooq, F., \& Jan, Z. (2012). The Impact of Social Networking to Influence Marketing through Product Reviews. ICT Journal, 2(8), 11.

Gony, J. (2007). Retin Smart Interactive Digital Media Retrieval System.

Ha, A. (2015). An Experiment: Instagram Marketing Techniques and Their Effectiveness. Jurnal Komunikasi, 2(1), 30.

Hamdan, Y., Ratnasari, A., Sofyan, A., \& Tandika, D. (2017). Promosi Bisnis untuk Meningkatkan Omzet Penjualan. Inter Komunika: Jurnal Komunikasi, 2(2), 108-113.

Kaplan, A. M., \& Haenlein, M. (2012). Social media: Back to the roots and back to the future. Journal of Systems and Information Technology, 14(2), 101-104.

https://doi.org/10.1108/13287261211 $\underline{232126}$

Nhung, Nguyen Phuong. (2011).Effectiveness of Consumer Endorser in Social Media Advertisement Impact on consumers" attitudes and behaviors. $8(1)$.

Schivinski, B. (2013). Effects of Social Media Communication on Brand Equity and Brand Purchase Intention. PhD Interdisciplinary Journal, 6.

Tarigan, R., \& Tritama, H. B. (2016). The
Effect of Social Media to The Brand Awareness of A Product of A Company. CommIT (Communication and Information Technology) Journal, 10(1), 6.

Yonaldi, S., \& Yanti, B. (2014). Analisis Communitization sebagai New Wave Marketing Strategy (Studi Pengguna Blackberry di Sumatra Barat). Jurnal Ekonomi. 